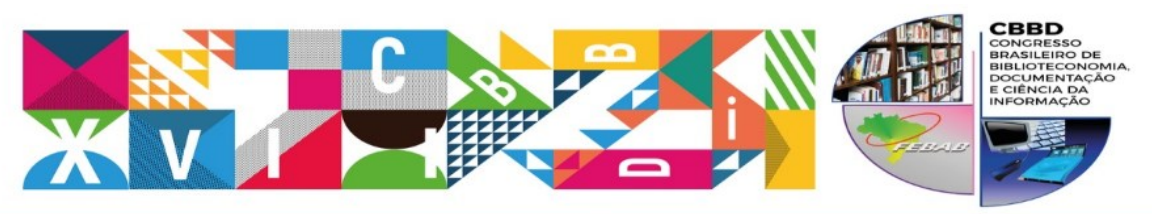

XXVII CONGRESSO BRASILEIRO DE BIBLIOTECONOMIA,

DOCUMENTAÇÃOO E CIÊNCIA DA INFORMAÇÃO

TEMA CENIRAL: Objetivos para o Desenvolvimento Sustentável das Naçōes Unidas:
como as bibliotecas podem contribuir com a implementação da Agenda 2030

Eixo 8 - Advocacy, Inovação e Empreendedorismo

\title{
A ECONOMIA CRIATIVA NA BIBLIOTECONOMIA
}

\section{Carla Daniella Teixeira \\ Girard \\ Bibliotecária da Universidade Federal Rural da Amazônia, campus \\ Paragominas. Mestra em Ciência da \\ Informação pela Universidade \\ Federal da Paraíba. \\ E-mail: carlinhagirard@yahoo.com.br}

\section{Diego Leonardo de Souza Fonseca}

Bibliotecário do Instituto Federal de Educação, Ciência e Tecnologia do Amazonas. Mestre em Engenharia de Produção pela Universidade Federal do Amazonas.

E-mail: diego.fonseca@ifam.edu.br

\section{Merabe Carvalho Ferreira da Gama}

Bibliotecária da Universidade Federal Rural da Amazônia. Mestra em Gestão Pública pela Universidade Federal do Pará.

E-mail:

merabecarvalho@yahoo.com.br

\section{RESUMO}

Este artigo tem como temática a economia criativa voltada à área da Biblioteconomia. Sendo assim, o objetivo deste estudo visa apresentar alguns empreendimentos na área da Biblioteconomia que se inserem no cenário da economia criativa. Para nortear a concretização do objetivo proposto foi utilizada uma pesquisa bibliográfica, empírica, descritiva e exploratória a partir de quatro negócios que aplicam a economia criativa na Biblioteconomia. As informações coletadas sobre cada empreendimento foram apresentadas em uma tabela, na qual teve o objetivo de identificar os nichos de atuação no mercado, período de atividade, serviços e produtos, foco de criativa e os seus canais de comunicação. Conclui-se, diante disto, que esta pesquisa fomente outros estudos sobre este tema e permitam que outros profissionais da informação reflitam sobre a economia criativa na Biblioteconomia como uma nova alternativa de atuação do mercado atual.

Palavras-chave:

Economia

criativa.

Biblioteconomia. Empreendedorismo

\section{THE CREATIVE ECONOMY IN LIBRARIANSHIP}

\section{ABSTRACT}

This article has as its theme the creative economy focused on the area of Librarianship. Therefore, the objective of this study is to present some projects in the area of librarianship that are part of the creative economy scenario. To guide the achievement of the proposed objective, a bibliographical, empirical, descriptive and exploratory research was used from four businesses that apply the creative economy in Librarianship. The information collected on each venture was presented in a table, in which the objective was to identify the niches of activity in the market, activity period, services and products, creative focus and their communication channels. It is concluded that this research foments other studies on this subject and allow other 


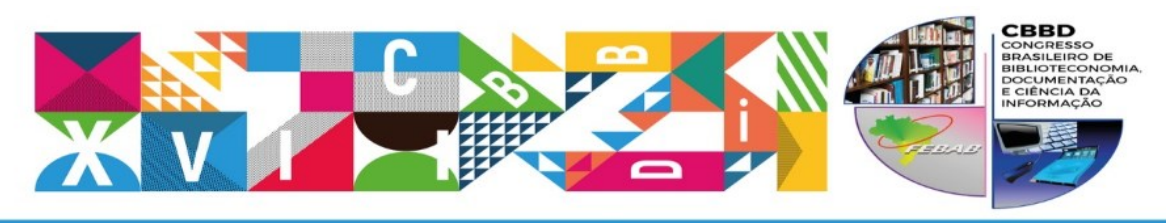

XXVII CONGRESSO BRASILEIRO DE BIBLIOTECONOMIA, DOCUMENTAÇÃ̃O E CIÊNCIA DA INFORMAÇÃO

TEMA CENIRAL: Objetivos para o Desenvolvimento Sustentável das Naçōes Unidas:
como as bibliotecas podem contribuir com a implementaçao da Agenda 2030

information professionals to reflect on the creative economy in Librarianship as a new alternative of current market performance.

Keywords: Creative economy. Librarianship. Business

\section{INTRODUÇÃo}

Ao longo do tempo a profissão de bibliotecário tem se transformado impulsionada por mudanças na área social, econômica e tecnológica (MOTA; OLIVEIRA, 2011). Essas transformações fomentam a necessidade do profissional assumir um papel criativo e inovador com o objetivo de fazer frente às exigências de seus usuários/clientes.

Entre os séculos XVII e XVIII a chamada Revolução Industrial foi caracterizada pela mudança na forma de produção, em razão de uma transição da manufatura,cujo insumo básico era a mão de obra e as matérias-primas, para a produção por máquinas em larga escala. No decorrer dos anos, mais precisamente no século XXI, a economia passou a sofrer novas concepções de produção, bem mais alinhadas com a sociedade da informação (MIGUEZ, 2007).

Assim, no pós-guerra e com o advento da Sociedade da Informação passou-se a exigir dos bibliotecários novas competências (MOTA; OLIVEIRA, 2011). Carvalhal e Muzzio (2015) destacam que há uma nova forma de produção, baseada no chamado capital intelectual, denominada de economia criativa. Esses autores a conceituam como um conjunto distinto de atividades pautadas na propriedade intelectual, cujos serviços e produtos, gerados em seus processos, potencializam as atividades assentadas na criatividade.

Galuk et al (2016) mencionam que a Conferência das Nações Unidas sobre Comércio e Desenvolvimento (UNCTD), realizada em 2008, destacou o crescimento do lucro no mercado da economia criativa em $\$ 595$ bilhões no mesmo ano, com uma projeção de crescimento dobrada para os próximos 5 anos.

Nesse contexto, a Biblioteconomia pode ser compreendida como uma área de atuação propensa ao desenvolvimento de serviços e produtos dentro do mercado da Revista Brasileira de Biblioteconomia e Documentação - v. 13, n. esp. CBBD 2017 


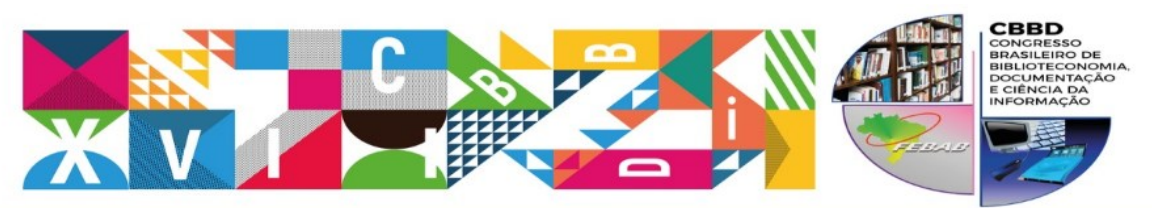

XXVII CONGRESSO BRASILEIRO DE BIBLIOTECONOMIA, DOCUMENTAÇÃO E CIÊNCIA DA INFORMAÇÃO

TEMA CENIRAL: Objetivos para o Desenvolvimento Sustentável das Naçōes Unidas:
como as bibliotecas podem contribuir com a implementaçao da Agenda 2030

economia criativa.Desse modo, esse artigo tem por objetivo apresentar alguns empreendimentos na área da Biblioteconomia que se inserem no cenário da economia criativa, uma vez que as transformações da sociedade têm impactado diretamente na profissão de bibliotecário.

Assim, nessa perspectiva é importante que o bibliotecário inove ao aliar as ferramentas biblioteconômicas tradicionais às novas exigências do seu público, seja ele composto por usuários tradicionais de bibliotecas ou até mesmo clientes de um empreendimento.

Para atender ao seu objetivo este artigo foi organizado em sete seções, além desta introdutória. A segunda seção apresenta o método da pesquisa. Já a terceira aborda a Sociedade da Informação. Para o tema central deste artigo, economia criativa, foram dedicadas a quarta e quinta seções, sendo que esta última aborda a economia criativa na biblioteconomia. Em seguida, na sexta seção são apresentadas as discussões do trabalho. Por fim, a sétima seção apresenta as considerações finais.

\section{MÉTODO DA PESQUISA}

Quanto aos procedimentos metodológicos, o estudo aplicou uma pesquisa bibliográfica a fim de realizar o levantamento bibliográfico da pesquisa pautado na revisão de literatura sobre: economia criativa e empreendedorismo. A pesquisa pode ser considerada empírica, descritiva e exploratória.

Quanto aos objetivos, é uma pesquisa observacional. Seu recorte é direcionado aos empreendimentos na biblioteconomia que desenvolvem atividades de expertise pautadas na economia criativa.

Foi feito um levantamento dos empreendimentos na área da Biblioteconomia que mais estão inseridas no mercado da economia criativa. Os dados sobre os serviços, produtos e tipologias de nicho de mercado dos empreendimentos foram coletados através de pesquisas em suas redes sociais e nos seus respectivos sites. 


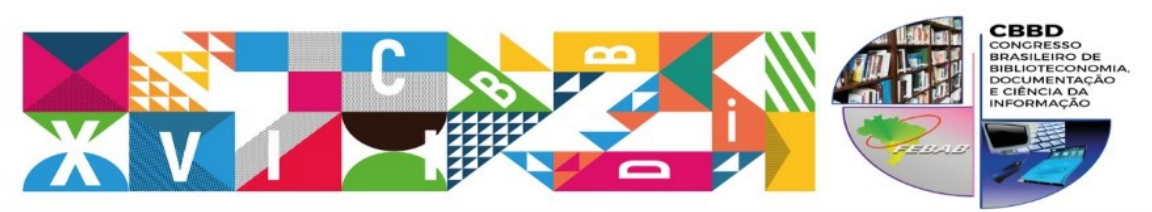

XXVII CONGRESSO BRASILEIRO DE BIBLIOTECONOMIA,

DOCUMENTAÇÃO E CIÊNCIA DA INFORMAÇÃO

TEMA CENTRAL: Objetivos para o Desenvolvimento Sustentável das Naçōes Unidas:
como as bibliotecas podem contribuir com a implementação da Agenda 2030

\section{SOCIEDADE DA INFORMAÇÃO}

Historicamente, a sociedade perpassou por modificações importantes quanto ao seu modo de produção. A sociedade pré-industrial tinha por base a produção de manufatura, incorporada pelo trabalho braçal e pelo inicio da mecanização. Bell (1977) afirma que a sociedade pré-industrial seria basicamente agrária, extrativista e predominantemente pautado nos serviços menos técnicos e com baixa produtividade de escala.

Em meados do século XVIII com a Revolução Industrial houve uma significante mudança no modo de produção global. Asociedade industrial, em contrapartida ao período econômico anterior, tinha as suas relações de trabalho baseado na produção em larga escala e na mecanização da produção, com o poder ligado ao capital e aos resultados produtivos (MARCHI, 2000).

Sobre a sociedade industrial:

A sociedade cuja organização do trabalho é industrial vem desde meados do século XVIII e podemos considerar que vigora até os dias atuais. É fato que é uma forma societal inédita, pois analisando toda a história humana, comprovar-se-á que nunca existiu organização similar. Nesta configuração nova a Revolução Industrial foi essencial, pois promoveu a produção de mercadorias de modo que fossem relativamente superados os imperativos naturais; conseguiu-se, a partir deste momento, um distanciamento, uma relativa independência, dos limites e exigências que a natureza impunha ao trabalho. Há séculos os homens buscam maneiras de produzir energia que sejam alternativas às formas naturais. Procura-se a separação do vínculo existente entre a produção de energia e a natureza (MARCHI, 2000, p. 116).

A produção alicerçada na sociedade industrial era moldada no resultado, sem foco sobre a qualidade nos meios de produção e, principalmente, na formação do trabalhador. As preocupações no processo produtivo se restringiam a quantificação produtiva para atender ao crescimento da demanda, sem atentar ao modo criativo, ficando restrito somente ao resultado. 


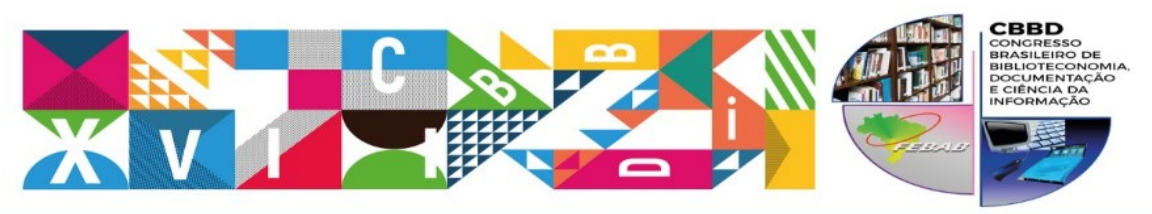

XXVII CONGRESSO BRASILEIRO DE BIBLIOTECONOMIA, DOCUMENTAÇÃO E CIÊNCIA DA INFORMAÇÃO

TEMA CENTRAL: Objetivos para o Desenvolvimento Sustentável das Naçōes Unidas:
como as bibliotecas podem contribuir com a implementaçăo da Agenda 2030

Após todo o processo de desencadeamento da produção a partir do surgimento de novos moldes econômicos, surgiu a chamada "sociedade da informação". Castells (2000) afirma que esse termo passou a ser utilizado nos últimos anos do século XX e no início do século XXI como termo substitutivo para a sociedade pós-indústrial, a fim de apresentar um conceito bem mais complexo, construindo a partir da concepção dos novos paradigmas tecno-econômicos.

Whertein (2000) argumenta que o fortalecimento dessa nova sociedade teve a sua estruturação afirmada em meados da década de 80 com a expansão e restruturação do capitalismo, principalmente pelo surgimento das novas tecnologias e dos primeiros conceitos centrados na inovação organizacional. Castell (2000, p. 34) configura esse cenário apresentando as seguintes características fundamentais da sociedade da informação:

A informação é sua matéria-prima: as tecnologias se desenvolvem para permitir o homem atuar sobre a informação propriamente dita, ao contrário do passado quando o objetivo dominante era utilizar informação para agir sobre as tecnologias, criando implementos novos ou adaptando-os a novos usos.

- Os efeitos das novas tecnologias têm alta penetrabilidade porque a informação é parte integrantede toda atividade humana, individual ou coletiva e,portanto todas essas atividades tendem a seremafetadas diretamente pela nova tecnologia.

- Predomínio da lógica de redes. Esta lógica, característica de todo tipo de relação complexa, pode ser, graças às novas tecnologias, materialmente implementada em qualquer tipo de processo.

- Flexibilidade: a tecnologia favorece processos reversíveis, permite modificação por reorganização de componentes e tem alta capacidade de reconfiguração.

- Crescente convergência de tecnologias, principalmente a microeletrônica, telecomunicações, optoeletrônica, computadores, mas também e crescentemente, a biologia. 0 ponto central aqui é que trajetórias de desenvolvimento tecnológico em diversas áreas do saber tornam-se interligadas e transformam-se as categorias segundo as quais pensamos todos os processos.

Esse novo paradigma estabeleceu como marco histórico na economia global o conceito de valorização da produção a partir da implementação do conceito de 


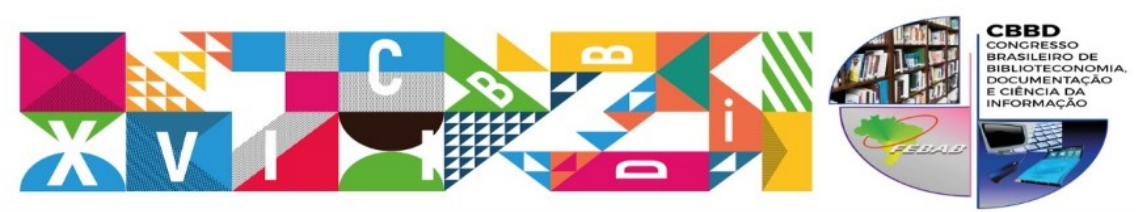

XXVII CONGRESSO BRASILEIRO DE BIBLIOTECONOMIA, DOCUMENTAÇÃO E CIÊNCIA DA INFORMAÇÃO

TEMA CENIRAL: Objetivos para o Desenvolvimento Sustentável das Naçōes Unidas:
como as bibliotecas podem contribuir com a implementação da Agenda 2030

investimento na capacidade intelectual da mão de obra, onde as novas tecnologias assumiram o papel de fomentadores desse novo processo produtivo.

\section{A ECONOMIA CRIATIVA}

Criatividade é a palavra que define múltiplas e intuitivas formas e capacidade de criar o novo, reinventar o que já existe, diluir paradigmas tradicionais e trazer soluções para diferentes contextos. Reis (2008) aborda que a economia criativa absorve o poder de resgatar a essência e transformar algo comum e um bem de grande valor com a finalidade de transformar os espaços.

O próprio conceito da economia criativa surge no bojo das transformações sociais, culturais e, principalmente, econômicas. Reis $(1998$, p.16) contextualiza que:

0 conceito de economia criativa origina-se do termo indústrias criativas, por sua vez inspirado no projeto Creative Nation, da Austrália, de 1994. Entre outros elementos, este defendia a importância do trabalho criativo, sua contribuição para a economia do país e o papel das tecnologias como aliadas da política cultural, dando margem à posterior inserção de setores tecnológicos no rol das indústrias criativas. Em 1997, o governo do então recém-eleito Tony Blair, diante de uma competição econômica global crescentemente acirrada, motivou a formação de uma forçatarefa multissetorial encarregada de analisar as contas nacionais do Reino Unido, as tendências de mercado e as vantagens competitivas nacionais. Segundo o então Secretário de Cultura do Reino Unido, Chris Smith, a iniciativa representava um exercício praticamente único no governo - transversal às tradicionais divisões de Whitehall2, unindo governo e indústria em uma parceria e definindo uma agenda com temas específicos.

A economia criativa surgiu em um contexto de revitalização da forma de produção em meio ao transicionamento de um mercado tradicional para um mercado mais plural e complexo. Boltanski e Chiapello (2002) diz que as indústrias criativas são modelos de produção pautados na concepção da capacidade intelectual humana de produzir conteúdos a partir da sua própria ótica e conhecimento. 0 papel dessas indústrias teve um peso 


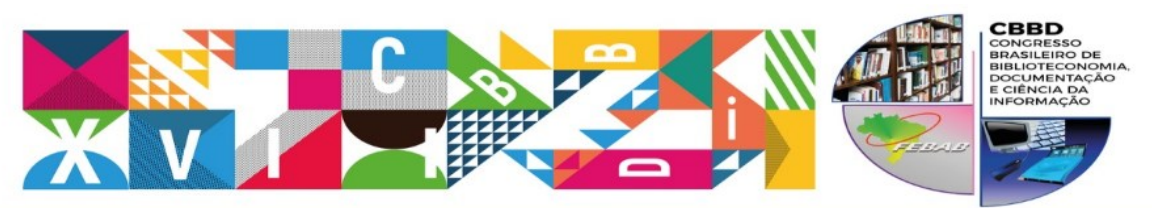

XXVII CONGRESSO BRASILEIRO DE BIBLIOTECONOMIA, DOCUMENTAÇÃO E CIÊNCIA DA INFORMAÇÃO

TEMA CENIRAL: Objetivos para o Desenvolvimento Sustentável das Naçōes Unidas:
como as bibliotecas podem contribuir com a implementaçáo da Agenda 2030

enorme na ampliação do dimensionamento da reestruturação do capital, tendo em vista o seu modelo direcionado ao perfil da sua demanda.

Entende-se então que o termo "economia criativa" é recente, em comparado a outras terminologias. 0 termo foi lançado pelo inglês John Howkings, no livro "The Creative Economy", ganhando força na crise dos anos 60 e tendo o seu ápice na década de 80 . Furtado (1984) abordou que a criatividade, inovação e os aspectos culturais fazem parte de um sistema que se combinam entre sí para desenvolver forças produtivas e gerar novos resultados. O "ser criativo", segundo o mesmo autor, refere-se ao chamado "gênio inventivo" que é a figura capaz de transformar um contexto aparentemente normal em algo produtivo e diferente.

Arrighi (2000) aborda sobre o conceito de inovação do ponto de vista do conhecimento técnico e do conhecimento intelectual. A trilogia "invenção-inovação-difusão" diz respeito a desencadeamento de ações que promovem o desenvolvimento econômico e corroboram para o surgimento de novos processos na sociedade. Assim sendo, a inovação é uma etapa crucial para a transformação dos paradigmas, que darão suporte a novos ciclos de produção do capital financeiro e intelectual.

Nicolaci-da-Costa (2014) afirma que a economia criativa pode ser compreendida como uma área em expansão pautada nas inovações. São exemplos de nichos de mercado da economia criativa: moda, jogos eletrônicos, consultoria em negócios na web, design, mercado audiovisual, dentre outros.Não obstante, a economia criativa vem absorvendo cada dia mais outras áreas que buscam aprimorar em seus conceitos uma nova modalidade de negócio baseado na inovação de mercado.

\section{ECONOMIA CRIATIVA NA BIBLIOTECONOMIA}

O campo da informação está intrinsicamente ligado às ações criativas e ao modelo de inovação de mercado que contrapõe ao modelo tradicional. As empresas estão buscando 


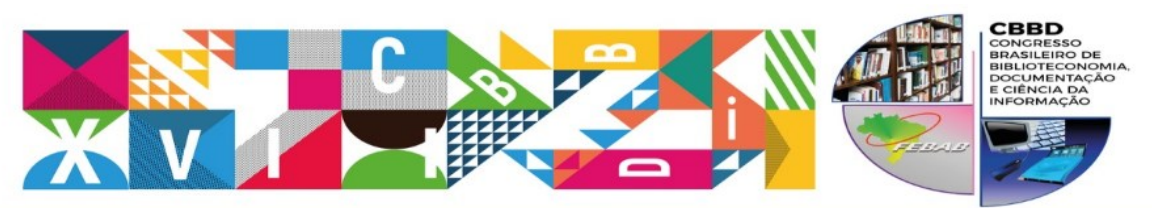

XXVII CONGRESSO BRASILEIRO DE BIBLIOTECONOMIA, DOCUMENTAÇÃO E CIÊNCIA DA INFORMAÇÃO

TEMA CENIRAL: Objetivos para o Desenvolvimento Sustentável das Naçōes Unidas:
como as bibliotecas podem contribuir com a implementaçáo da Agenda 2030

investir cada vez mais em modelos de negócios que atentem ao foco da qualidade dos serviços e produtos valorizando o capital intelectual.

No âmbito da Biblioteconomia, alguns nichos de mercado vêm ganhando cada vez mais espaço no desenvolvimento de empreendimentos e na proposição de novas ideias de negócio no campo da economia criativa. Os conceitos do marketing e do empreendedorismo ganharam espaço no mercado de trabalho e o bibliotecário vem atuando frente a esse novo panorama.

Spudeit (2016) aborda o conceito de empreendedorismo na Biblioteconomia como uma vertente de perspectiva que amplifica as formas de atuação do bibliotecário no mercado. A economia criativa centra-se justamente na produção fomentada pelo capital intelectual e por novos parâmetros de inovação que o mercado possibilita.

0 mercado de trabalho é mutável e os profissionais que trabalham com o capital intelectual estão sendo moldados nesse novo contexto de trabalho. Mas e o bibliotecário, qual papel ele vem assumindo? Lankes (2012) afirma que a atuação do bibliotecário vai além da concepção tradicionalista, que os espaços de atuação precisam ser ocupados para que novas reflexões e identidades sejam formadas.

Dentre os espaços de atuação da economia criativa na Biblioteconomia, podem ser citados: blogs,com o oferecimento de cursos preparatórios para concursos públicos, agência de publicações, como veículo de informações sobre a área, produtos de moda, designer de marca profissional, empresa que oferece cursos de capacitação e qualificação profissional, dentre outros.

\subsection{Santa Biblioteconomia}

O Santa Biblioteconomia é um blog que foi criado em 2012 pela bibliotecária Thalita Gama, graduada em Biblioteconomia pela Universidade Federal do Rio de Janeiro (UFRJ). 0 objetivo inicial do blog foi de compartilhar os seus aprendizados e auxiliar os bibliotecários sobre os assuntos relacionados ao curso de Biblioteconomia. 

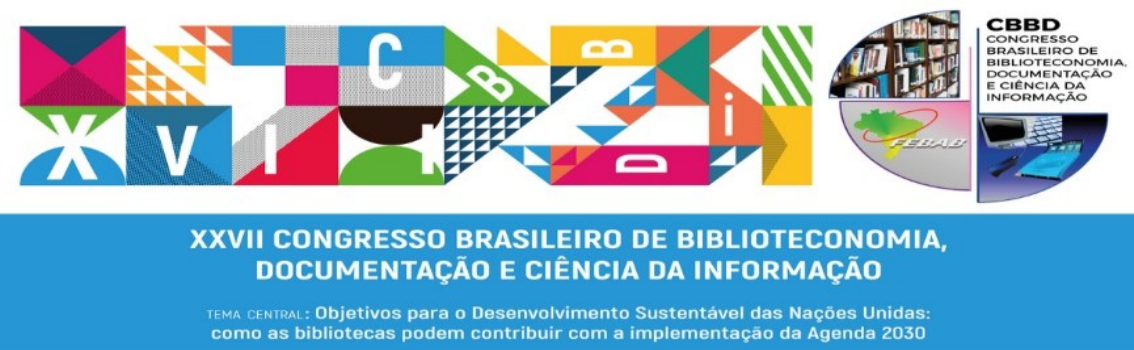

O blog não apenas realiza postagens inerentes ao universo da Biblioteconomia, mas também elabora apostilas de estudo com foco em concurso público, que é o seu grande referencial. Atualmente, são oferecidos diversos cursos preparatórios para concursos públicos na área da Biblioteconomia por todo o Brasil, alguns já realizados nas próprias cidades e outros realizados à distância.

Figura 1 - Parceria para a realização de atividade

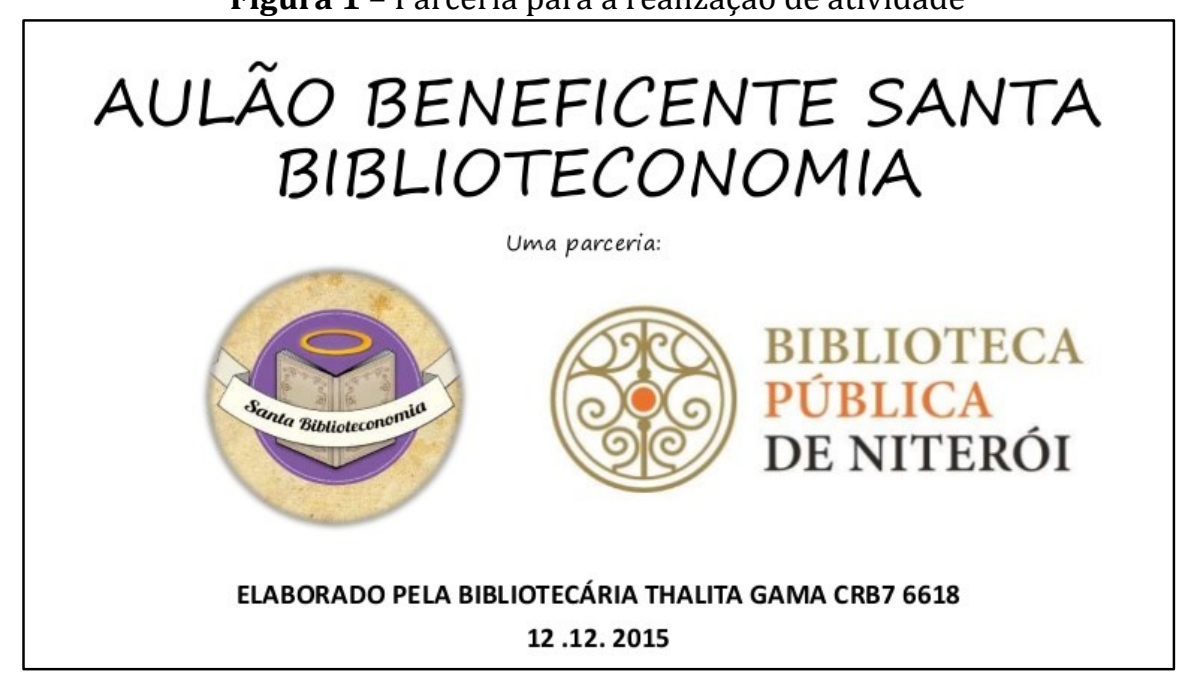

Fonte: Blog Santa Biblioteconomia (2015).

A criação do blog pode ser compreendida como uma estratégia de inovação de mercado para atender a uma demanda cada dia mais crescente na área: a busca por uma vaga no serviço público. Mediante a esse cenário, o alcance aos interessados em participar dos cursos foi realizado através das redes sociais com o marketing digital. 0 site do blog (https://santabiblioteconomia.com) oferece todas as informações inerentes aos serviços e produtos oferecidos, bem como a trajetória acadêmica de sua idealizadora e a agenda dos seus cursos preparatórios. 


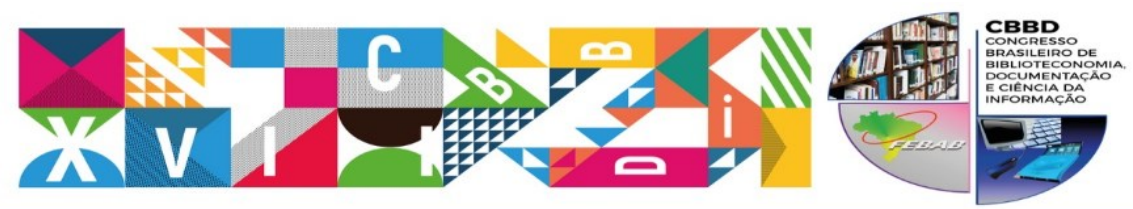

XXVII CONGRESSO BRASILEIRO DE BIBLIOTECONOMIA, DOCUMENTAÇÃO E CIÊNCIA DA INFORMAÇÃO

TFMA CENTRAL: Objetivos para o Desenvolvimento Sustentável das Naçōes Unidas:
como as bibliotecas podem contribuir com a implementação da Agenda 2030

\subsection{Class Cursos}

A Class Cursos é uma empresa que tem por objetivo promover cursos de aperfeiçoamento e desenvolvimento profissional na área da Biblioteconomia e Ciência da Informação. Ela foi fundada em 2015 e buscou apresentar cursos organizados e desenvolvidos por professores capacitados nas referidas áreas através da plataforma online e do acompanhamento oferecido pela empresa.

A empresa foi criada pelo bibliotecário e diretor executivo, Cauê Araújo, formado em Biblioteconomia pela Universidade Federal do Ceará(UFC) e tem em sua equipe um profissional da área da Tecnologia da Informação. A empresa oferece dentre os seus serviços e produtos os Cursos in Company, com o objetivo de levar cursos de qualificação profissional para as empresas e seus colaboradores (https://www.classcursos.com).

Figura 2 - Divulgação dos cursos online

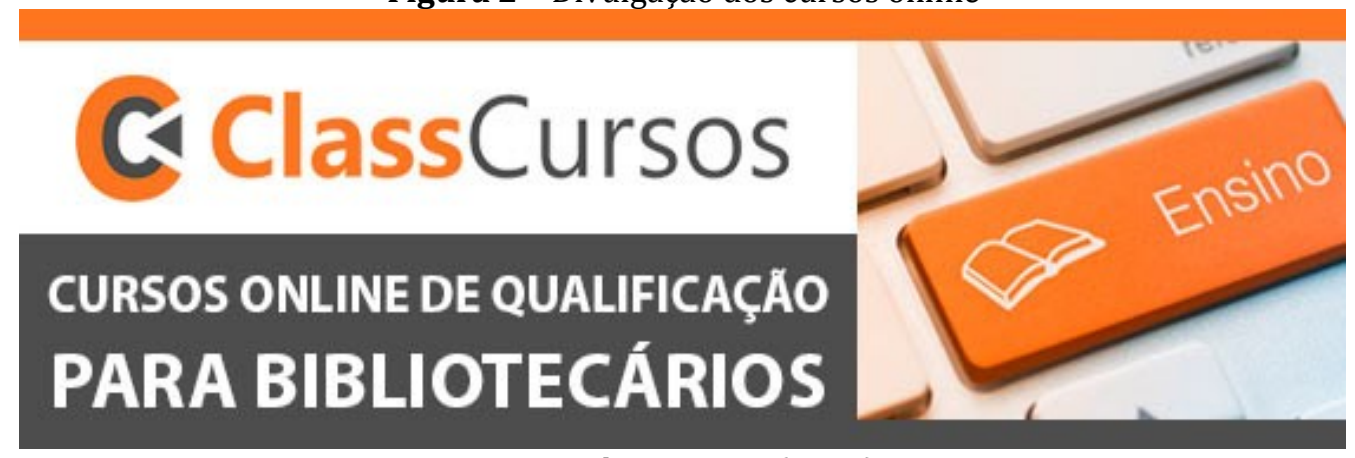

Fonte: Class Cursos (2016).

Os cursos oferecidos pela empresa atendem as principais subáreas da Biblioteconomia e da Ciência da Informação: Auxiliar de Biblioteca, Coaching para bibliotecários; Preparatório para concursos públicos; E-books; Gestão do Conhecimento; Normalização, dentre outros. A empresa ainda realiza parcerias com instituições de ensino, empresas e associações de bibliotecários para o oferecimento dos cursos e divulgação da sua marca. 


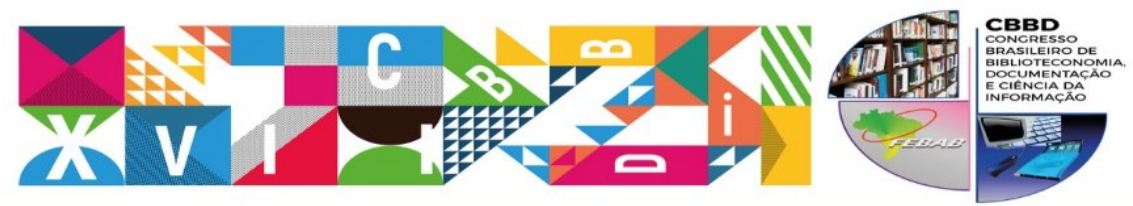

\section{CONGRESSO BRASILEIRO DE BIBLIOTECONOMIA, DOCUMENTAÇÃO E CIÊNCIA DA INFORMAÇÃO \\ TFMA CENTRA: : Objetivos para o Desenvolvimento Sustentável das Naçōes Unidas:
como as bibliotecas podem contribuir com a implementação da Agenda 2030}

A estratégia de mercado observada na empresa vem atender a demanda da qualificação profissional do bibliotecário, que é um setor de mercado que ainda carece de empresas que ofereçam cursos de capacitação EaD e semipresencial. No cenário da economia criativa a Class Cursos atende a uma demanda de inovação bastante peculiar e ainda pouco explorada na Biblioteconomia: o mercado de cursos online.

\subsection{Agência Biblioo: Publicações e Comunicação}

A Agência Biblioo é uma empresa do ramo da publicação e comunicação com enfoque nas áreas de Biblioteconomia, Cultura, Educação e Literatura. Criado desde 2011 tem como um dos seus principais produtos a Revista Biblioo(http://biblioo.cartacapital.com.br/edicoes/) e as publicações do site Biblioo (http://biblioo.cartacapital.com.br/) que recentemente fechou uma parceria com a Revista Carta Capital.

A empresa realiza diversas coberturas de eventos e programações inerentes à área da Biblioteconomia, divulgando em seu site inúmeras reportagens com profissionais que atuam na área e instituições que promovem a profissão. 0 seu foco na produção de conteúdo corroborou para que ela se consolidasse como um dos principais meios de comunicação e mídia da Biblioteconomia no cenário profissional atual. 


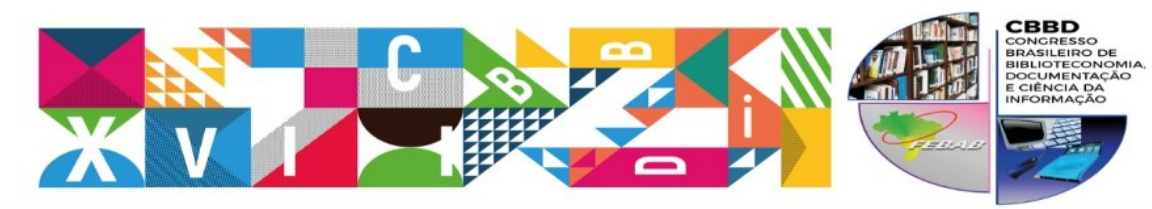

\section{CONGRESSO BRASILEIRO DE BIBLIOTECONOMIA, DOCUMENTAÇÃO E CIÊNCIA DA INFORMAÇÃO \\ TFMA CFNIRAL: Objetivos para o Desenvolvimento Sustentável das Naçōes Unidas:
como as bibliotecas podem contribuir com a implementação da Agenda 2030}

Figura 3 - Revista Biblioo (Caderno Especial)

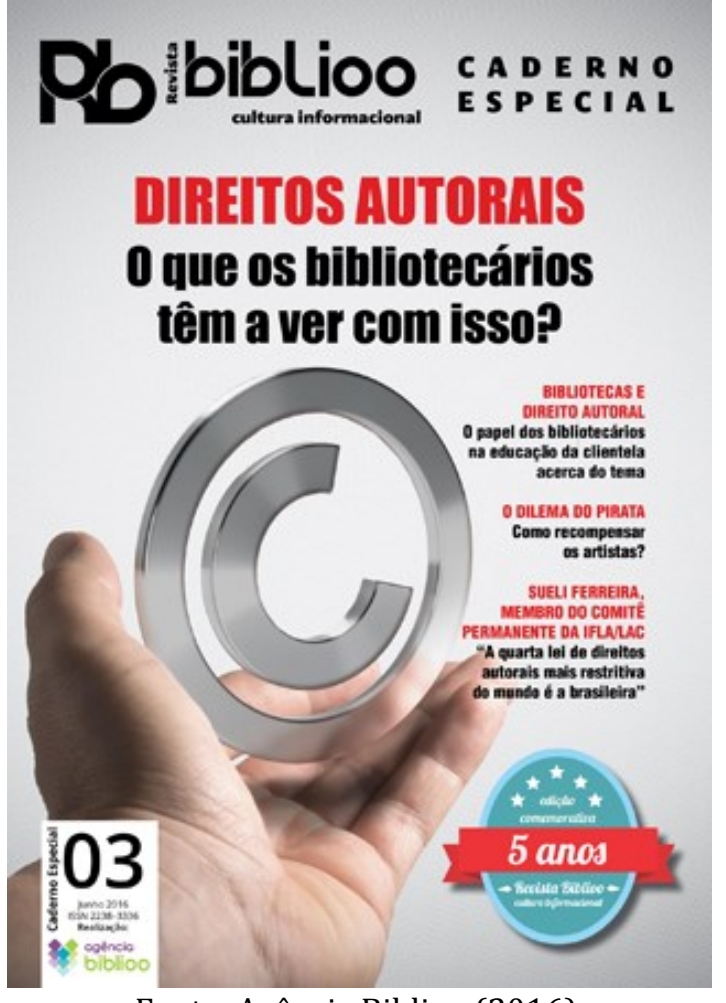

Fonte: Agência Biblioo (2016).

O diferencial da empresa está na proposta de negócio oferecida a um nicho de mercado específico: divulgação e cobertura jornalística. Observa-se que até então nas áreas da Biblioteconomia eCiência da Informação não existia, pelo menos a um nível mais abrangente, uma agência direcionada para a mídia e divulgação na cobertura dos eventos e da produção cultural e profissional da área, sendo assim vista como uma oportunidade de negócio a partir de um insight criativo.

\subsection{T-Shirts - Mural}

A T-Shirts Mural é uma loja online especializada em $t$-shirts (blusas) personalizadas segmentadas para profissionais e simpatizantes da Biblioteconomia e áreas afins. A ideia 

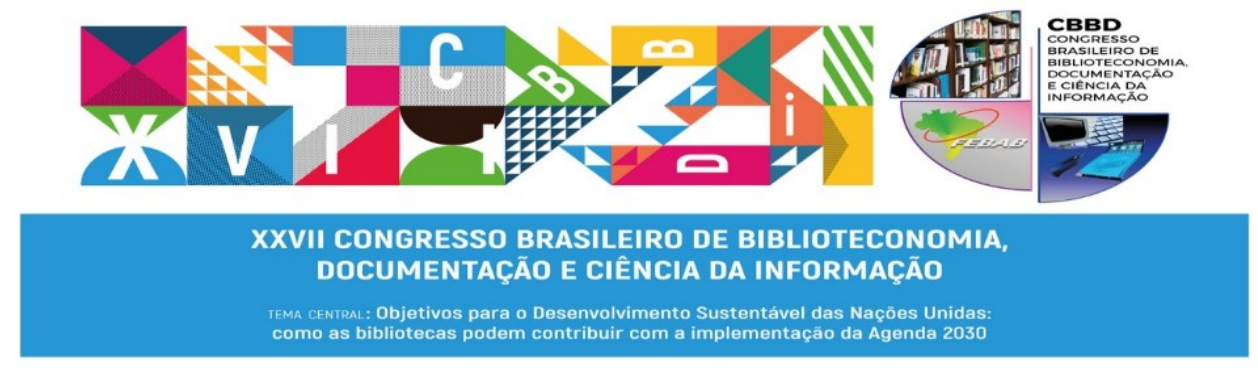

surgiu a partir da fan page Mural Interativo do Bibliotecário no Facebook, com o objetivo de fortalecer a imagem da área e potencializar a identidade da profissão.

O empreendimento foi criado em 2014 pela bibliotecária Fabíola Bezerra, que atuou como bibliotecária da UFC. A percepção da marca denota a importância que a empresa demonstra com relação a identidade profissional e com um mix de empreendedorismo aliando inovação, moda e tendências de mercado.

Além das camisas, a empresa oferece outros produtos que apostam na marca profissional a partir de imagens e artefatos personalizados: canecas, chinelos, coleções especiais e livros. Os produtos são vendidos diretamente pelo site (http://www.tshirtsmural.com.br/) e também em stands em alguns eventos profissionais de Biblioteconomia e Ciência da Informação.

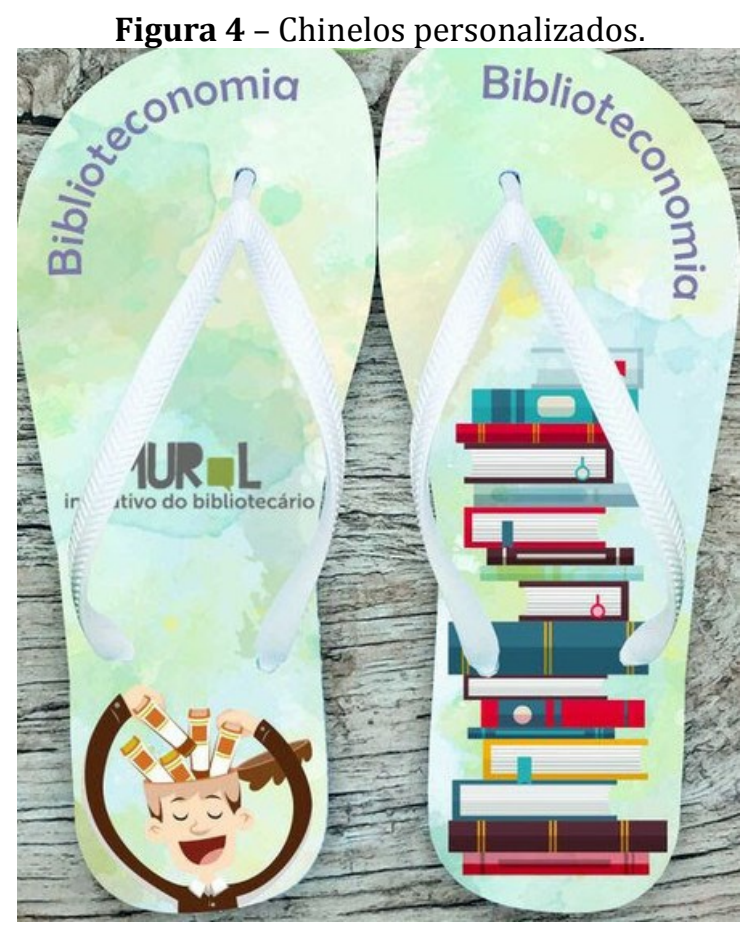

Fonte: T-Shirts Mural (2017).

A T-Shirts Mural apostou no nicho de mercado de moda e designer personalizado para uma área profissional. A criatividade na confecção das blusas e criação de coleções Revista Brasileira de Biblioteconomia e Documentação - v. 13, n. esp. CBBD 2017 


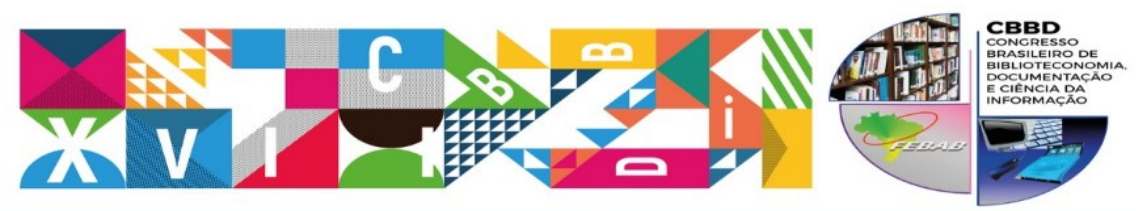

$$
\begin{aligned}
& \text { XXVII CONGRESSO BRASILEIRO DE BIBLIOTECONOMIA, } \\
& \text { DOCUMENTAÇÃO E CIÊNCIA DA INFORMAÇÃO } \\
& \text { TEMA CENIPAs: Objetivos para o Desenvolvimento Sustentável das Naçōes Unidas: } \\
& \text { como as bibliotecas podem contribuir com a implementaçào da Agenda } 2030
\end{aligned}
$$

especiais com temática intuitiva denota um exemplo de indústria criativo que aliou inovação e identidade profissional para atender a uma demanda consumidora de produtos que valoriza a sua profissão.

De acordo com o levantamento dos empreendimentos reunidos na pesquisa, a tabela

\begin{tabular}{|c|c|c|c|c|}
\hline & Santa Biblioteconomia & Class Cursos & $\begin{array}{l}\text { Agência Biblioo } \\
\text { Publicações e } \\
\text { Comunicação }\end{array}$ & T-Shirts Mural \\
\hline $\begin{array}{c}\text { Nicho } \\
\text { de mercado }\end{array}$ & $\begin{array}{l}\text { Blog com o oferecimento de } \\
\text { cursos preparatórios para } \\
\text { concursos públicos }\end{array}$ & $\begin{array}{l}\text { Cursos de capacitação e } \\
\text { qualificação profissional }\end{array}$ & $\begin{array}{l}\text { Agência de publicações } \\
\text { sobre a área de } \\
\text { Biblioteconomia }\end{array}$ & $\begin{array}{c}\text { Loja online de } \\
\text { produtos de moda e } \\
\text { designer da marca } \\
\text { profissional } \\
\text { (Biblioteconomia) } \\
\end{array}$ \\
\hline $\begin{array}{l}\text { Serviços e } \\
\text { produtos }\end{array}$ & $\begin{array}{c}\text { Apostilas para estudo; } \\
\text { Cursos preparatórios para } \\
\text { concursos públicos na área de } \\
\text { Biblioteconomia }\end{array}$ & $\begin{array}{l}\text { Cursos in company } \\
\text { Cursos preparatórios } \\
\text { específicos para } \\
\text { Biblioteconomia }\end{array}$ & $\begin{array}{c}\text { Publicações de livros; } \\
\text { Suporte de organização, } \\
\text { cobertura e divulgação de } \\
\text { eventos; } \\
\text { Produção de conteúdo; } \\
\text { Cursos e criação de sites, } \\
\text { filmagens e reportagens }\end{array}$ & $\begin{array}{c}\text { T-shirts especializadas } \\
\text { Canecas } \\
\text { Sandálias } \\
\text { Livros }\end{array}$ \\
\hline $\begin{array}{l}\text { Período de } \\
\text { atuação no } \\
\text { mercado }\end{array}$ & Desde 2013 & Não localizado & Desde 2011 & Desde 2014 \\
\hline $\begin{array}{c}\text { Foco de } \\
\text { criatividade }\end{array}$ & Concursos públicos & $\begin{array}{c}\text { Treinamento em } \\
\text { desenvolvimento } \\
\text { profissional e gerencial }\end{array}$ & Comunicação social & $\begin{array}{l}\text { Identidade e marca } \\
\text { profissional }\end{array}$ \\
\hline $\begin{array}{l}\text { Canais de } \\
\text { comunicação }\end{array}$ & $\begin{array}{c}\text { https://santabiblioteconomia.co } \\
\underline{\mathrm{m} /} \\
\text { Facebook: Santa } \\
\text { Biblioteconomia }\end{array}$ & $\frac{\underline{\text { http://www.classcursos.co }}}{\text { Facebook: } \frac{\mathrm{m} /}{\text { Class Cursos }}}$ & $\frac{\text { http://agencia.biblioo.info/ }}{\text { Facebook: Biblioo }}$ & $\begin{array}{l}\frac{\text { http://www.t- }}{\text { shirtsmural.com.br/ }} \\
\begin{array}{l}\text { Facebook: T-shirts } \\
\text { MURAL }\end{array}\end{array}$ \\
\hline
\end{tabular}
abaixo apresenta alguns dos cases de economia criativa na Biblioteconomia:

Tabela 1 - Cases de economia criativa na Biblioteconomia.

Fonte: Elaborado pelos autores (2017).

A partir dos empreendimentos apresentados acima, pode-se observar que a Biblioteconomia é uma área que oferece múltiplos campos de atuação. Nota-se que os nichos de mercado são variados e atendem a áreas de atuação distintas, tendo a Biblioteconomia como foco de criatividade. 


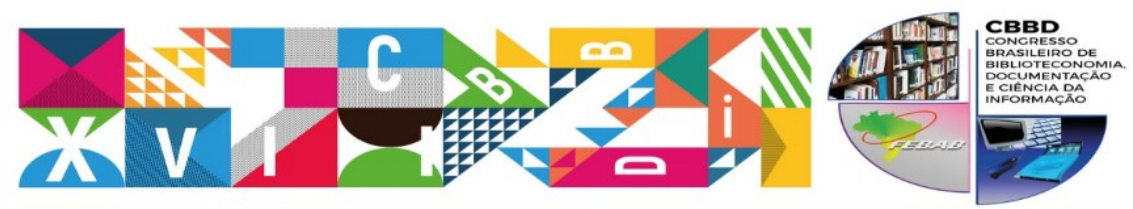

XXVII CONGRESSO BRASILEIRO DE BIBLIOTECONOMIA, DOCUMENTAÇÃ̃O E CIÊNCIA DA INFORMAÇÃO

TFMA CENTRA: : Objetivos para o Desenvolvimento Sustentável das Naçōes Unidas:
como as bibliotecas podem contribuir com a implementação da Agenda 2030

Os focos de criatividade foram compreendidos no estudo como a oportunidade de mercado para empreender uma ideia, ou seja, o chamado feeling ${ }^{1}$ do investimento. 0 período de atuação no mercado também denota uma recente iniciativa de implantação dos negócios, o que tende a ser mais presente nos próximos anos devido às oportunidades de mercado e ao desenvolvimento do empreendedorismo na Biblioteconomia.

\section{DISCUSSÃO}

O empreendedorismo é definido como a habilidade de conceber e estabelecer algo partindo de muito pouco ou quase nada, ou seja, é um processo de criação e desenvolvimento a partir de um negócio e que trará resultados a médio e longo prazo (BARRETO, 1998). Na Biblioteconomia, as ações empreendedoras estão cada vez mais presentes, assim como as discussões sobre novas ideias de empreendimentos no mercado atual (SPUDEIT, 2016).

A economia criativa vem estabelecendo vários caminhos promissores no mercado direcionado ao campo da Biblioteconomia. É importante ressaltar que os aspectos de inovação estão sendo inseridos aos poucos no perfil dos novos profissionais da informação, trazendo à luz da construção dos currículos acadêmicos a importância de estabelecer um perfil mais empreendedor na formação dos bibliotecários.

Gonçalves (2009) traça o perfil do profissional da informação, o bibliotecário, como um agente de transformação que possui as características de empreendedor e gestor. Essa característica traz ao bibliotecário uma expertise fundamental no campo do desenvolvimento de ideias, na criação de novos negócios, tendo a informação como matéria-prima.

\footnotetext{
${ }^{1}$ Termo utilizado no ramo dos negócios para representar uma oportunidade antevista no mercado (MIGUEZ, 2007).
} 


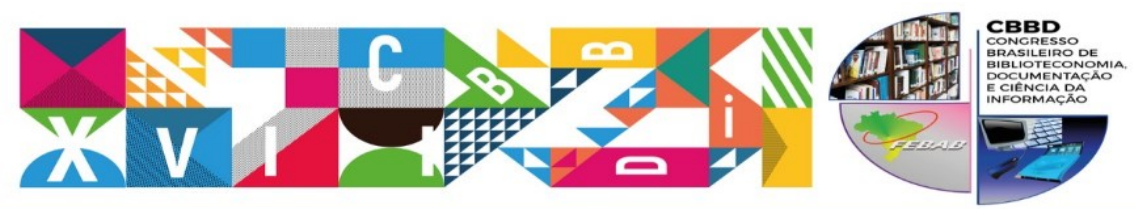

XXVII CONGRESSO BRASILEIRO DE BIBLIOTECONOMIA,

DOCUMENTAÇÃO E CIÊNCIA DA INFORMAÇÃO

TEMA CENTRAL: Objetivos para o Desenvolvimento Sustentável das Naçōes Unidas:
como as bibliotecas podem contribuir com a implementação da Agenda 2030

\section{CONSIDERAÇÕES FINAIS}

A pesquisa realizada tratou sobre o tema "Economia criativa e Biblioteconomia", a qual teve o seu desenvolvimento concretizado de forma contundente. Pretendeu apresentar alguns empreendimentos na área da Biblioteconomia que fazem parte do universo da economia criativa.

Portanto, pode-se entender que as modificações advindas da sociedade da informação proporcionaram uma nova maneira de visualizar o mercado, o que possibilitou que áreas como a Biblioteconomia pudessem desenvolver diversos ramos, como o empreendedorismo. Por isso, a economia criativa se faz presente nesse campo, já quefavoreceu aos bibliotecários um novo olhar sobre seus bens e serviços advindos do seu conhecimento profissional e que estão ganhando espaço no mercado.

Sendo assim, para mostrar esta aplicabilidade da economia criativa na Biblioteconomia, analisaram-sequatro negócios referentes à área, que investiram na economia criativa. Nessas análises, buscou-se compreenderseus nichos de mercado, serviços e produtos, período de atuação no mercado, foco de criatividade e canais de comunicação.

Por fim, espera-se que esta pesquisa proporcione outros estudos e incentive o debate sobre o tema, ainda carente de discussões na Biblioteconomia. Acredita-se, por fim, que seria relevante,que outros profissionais da informaçãovislumbrem uma reflexão sobre a economia criativa na área, como uma nova possibilidade de atuação no mercado atual.

\section{REFERÊNCIAS}

BARRETO, L.P. Educação para o empreendedorismo. Salvador: Escola de Administração de Empresa da Universidade Católica de Salvador, 1998. 


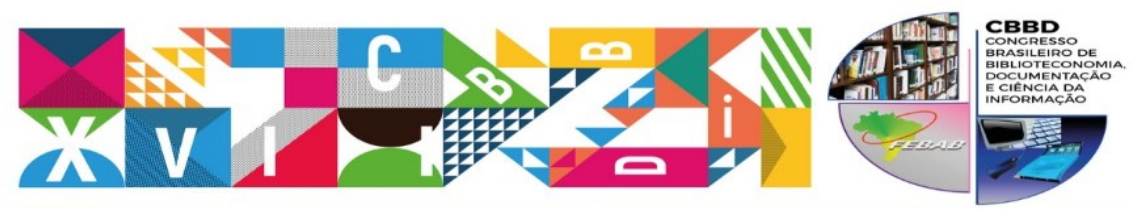

\section{CONGRESSO BRASILEIRO DE BIBLIOTECONOMIA, DOCUMENTAÇÃ̃O E CIÊNCIA DA INFORMAÇĀO \\ TEMA CENIRAL: Objetivos para o Desenvolvimento Sustentável das Naçōes Unidas:
como as bibliotecas podem contribuir com a implementaçăo da Agenda 2030}

CARVALHO, Felipe; MUZZIO, Henrique. Economia criativa e liderança criativa: uma Associação (IM) possível? REAd. Revista Eletrônica de Administração, v.21, n.3, p.659-688, 2015.

GALUK, Mariana Bianchini et al. Inovação em microempresas da economia criativa: um estudo de múltiplos casos. RAM, Rev. Adm. Mackenzie [online], v.17, n.5, p.166-187, 2016.

GONÇALVES, Pammella Emanoelle Camatini. Bibliotecário empreendedor. 57f. 2009. Trabalho de Conclusão de Curso (Graduação em Biblioteconomia) - Universidade Federal de Santa Catarina, Florianópolis, SC, 2009.

MOTA, Francisca Rosaline Leite; OLIVEIRA, Marlene de. Formação e atuação profissional. In: OLIVEIRA, Marlene de (Org.). Ciência da Informação e Biblioteconomia: novos conteúdos e espaços de atuação. 2. ed. Belo Horizonte: Editora UFMG, 2011.

MIGUEZ, Paulo. Economia criativa: uma discussão preliminar. In: NUSSBAUMER, Gisele Marchiori (Org.). Teorias e políticas da cultura: visões multidisciplinares. Salvador: EDUFBA, 2007. Coleção CULT, 1. p. 96-112.

NICOLACI-DA-COSTA, Ana Maria. Economia criativa, a Web 2.0 e o Vírus da exposição de talentos. Psicologia: ciência e profissão, v.34, n.4, p. 955-970, 2014.

SPUDEIT, Daniela (Org). Empreendedorismo na biblioteconomia. Rio de Janeiro: Agência Biblioo, 2016.

\section{AGRADECIMENTOS}

Aos responsáveis pelos empreendimentos mencionados no artigo pelas contribuições diretas e indiretas para a realização da pesquisa: Class Cursos, Santa Biblioteconomia, Agência Biblioo e T-Shirts Mural Interativo. 